\title{
As particularidades da reprodução do patrimônio cultural da comunidade quilombola de Palmital dos Pretos, \\ Campo Largo - PR
}

\author{
Las peculiaridades de la reproducción del patrimonio cultural \\ en la comunidad cimarrón de Palmital dos Pretos, \\ Campo Largo - PR
}

\section{The reproduction peculiarities of the cultural heritage in the quilombola community Palmital dos Pretos, Campo Largo - PR}

\author{
Maximillian Ferreira Clarindo \\ maxclarindo@hotmail.com \\ Doutorando do PPG em Geografia da UEPG
}

Nicolas Floriani

florianico@gmail.com

Professor Doutor do PPG em Geografia da UEPG

\begin{abstract}
Resumo: O texto explora as particularidades da reprodução do patrimônio cultural da comunidade quilombola de Palmital dos Pretos, localizada no distrito de Três Córregos, município de Campo Largo - PR. A comunidade pesquisada se amolda à histórica invisibilidade do negro no Estado e à segregação territorial e social das comunidades rurais tradicionais. Para obtenção dos resultados foram aplicadas três ferramentas do Diagnóstico Rural Participativo (DRP), bem como entrevistas às famílias quilombolas. Os métodos conduziram à conclusão de que as barreiras postas na reprodução do patrimônio cultural quilombola são, basicamente a desmedida ingerência externa na comunidade, hibridismo religioso e principalmente a morosidade na regularização fundiária às famílias.
\end{abstract}

Palavras-chave: Patrimônio cultural. Quilombolas. Território.

Resumen: El texto analiza las particularidades de la reproducción del patrimonio cultural en la comunidad quilombola de Palmital de Negros, ubicado en el distrito de Tres Arroyos, ciudad de Campo Largo - PR. La comunidad estudiada se ajusta a la invisibilidad histórica de los negros en el estado y también a la segregación territorial y social de las comunidades rurales tradicionales. Para obtener los resultados se aplicaron tres herramientas del Diagnóstico Rural Participativo (DRP), así como entrevistas con las familias cimarrones. Los métodos han llevado a la conclusión de que las barreras puestas en la reproducción del patrimonio cultural son básicamente: la interferencia externa desenfrenada en la comunidad, la hibridez religiosa y, especialmente, el retraso de regularización de la tierra a las familias.

Palabras-Clave: Patrimonio cultural. Cimarrones. Territorio. 


\begin{abstract}
This paper explores the reproduction peculiarities of the cultural heritage in the quilombola community Palmital dos Pretos situated in the Três Córregos district in Campo Largo - PR. The community studied is an example of the historical invisibility of blacks in the state of Paraná as the territorial and social segregation of its traditional rural communities. In order to carry out the study, it were employed three tools of Participatory Rural Appraisal (PRA) as well as interviews with quilombola families. The analysis demonstrates that the obstacles for the reproduction of the quilombola cultural heritage it were represented mainly by excessive external interference in the community, religious hybridism, and delays in regulating land.
\end{abstract}

Keywords: Cultural heritage. Quilombolas. Territory.

\title{
INTRODUÇÃO
}

Pretende-se com esta investigação identificar as particularidades da reprodução do patrimônio cultural da comunidade quilombola de Palmital dos Pretos frente a outros atores sociais na disputa pelo território. Como objetivos específicos, buscaremos descrever as particularidades culturais quilombolas a partir das comunidades existentes no $\mathrm{Pa}$ raná, bem como conhecer a comunidade de Palmital dos Pretos e discutir a ingerência da disputa pelo território na cultura quilombola.

A comunidade localiza-se na área rural do município de Campo Largo no Paraná. Em incursões à comunidade têm se observado que os remanescentes quilombolas daquela localidade são híbridos do ponto de vista cultural: surgem de um processo histórico de formação socioespacial da região dos campos gerais, que tem como especificidade a apropriação de espaços marginais aos grandes latifúndios dedicados à exploração extensiva de gado e a exploração da erva-mate, coexistindo com uma população de caboclos e imigrantes europeus na formação de sistemas voltados à pequena agricultura.

Da coexistência de categorias sociais ligadas a produção camponesa emergem os grupos remanescentes de quilombolas que carregam aspectos socioculturais herdados do hibridismo entre os descendentes de negros, indígenas, faxinalenses e agricultores familiares de origem europeia.

Estas comunidades, são a marca de uma história de exclusão e exploração de camadas populares, anterior à formação do Estado Nação Brasileiro. Na maioria das vezes suas estratégias de resistência frente aos projetos de Estado Nação incluem a invisibilidade das suas práticas sociais, de maneira a camuflar-se e assim permitir a sua reprodução sociocultural.

Por outro lado, as comunidades quilombolas mostram-se visíveis ao poder público e a outros atores sociais quando o contexto político permite a expressão da identidade e direitos pela apropriação do território. Essa situação ocorre atualmente no contexto político brasileiro onde as manifestações ocorrem conjuntamente entre os movimentos sociais, academia e setores do poder público.

A segregação territorial imposta a estas comunidades lhes impõem o desenvolvimento de estratégias de sobrevivência que possam fazer frente a inércia do poder público 
na prestação de serviços, como saúde pública. No caso de uma comunidade negra, como é Palmital dos Pretos, o preconceito soma-se à segregação territorial nas dificuldades em acessar o aparato estatal.

Com todas estas adversidades, que serão aprofundadas no transcorrer deste estudo, torna-se irrefragável que estas famílias tenham desenvolvido estratégias de sobrevivência de modo a fazer frente à negligência do Estado, tais estratégias correspondem ao patrimônio cultural quilombola.

O patrimônio cultural dessa população tradicional rural inclui práticas materiais (agricultura, tecnologias, etc.) e imateriais (saberes, rituais religiosos, dentre outras) e se encontra em processo contínuo de transformação. Não obstante, nas últimas décadas, a comunidade tem presenciado transformações drásticas em termos de estrutura fundiária e práticas produtivas, alterando sua relação com o território. Esse nível de transformação impossibilita o grupo de reproduzir-se biológica e culturalmente.

Para se identificar as adversidades e convergências que se colocam diante da comunidade na manutenção de sua cultura, é fundamental conhecer quais são as principais características culturais inerentes às comunidades quilombolas e a posição social em que se encontram atualmente, sendo que para isto, adotaremos como base alguns estudos relacionados às comunidades do Paraná.

É necessário também aprofundar o debate teórico entorno dos conceitos de cultura, patrimônio material e imaterial, com vistas a compreender os reais significados destes e o que realmente se busca conservar e identificar. Metodologicamente, foram realizadas várias visitas na comunidade valendo-se do método de observação participante, onde "não propõe mais do que andar com os olhos abertos e escutar mais do que falar, aproveitando as possibilidades de compartilhar alguns momentos do cotidiano com os agricultores" (VERDEJO, 2006, p. 22). Neste caso, dos membros da comunidade quilombola em geral.

Após o período de observação, foi possível ter uma ideia acerca de todo o contexto em que se insere a comunidade, a partir disso, aplicaram-se algumas ferramentas do Diagnóstico Rural Participativo (VERDEJO, 2006), as quais se mostraram as ferramentas metodológicas mais adequadas para o momento, bem como, foram realizadas algumas entrevistas.

Sendo assim, este texto traz na primeira seção a análise generalista dos quilombolas existentes no estado do Paraná na atualidade, bem como o histórico da comunidade de Palmital dos Pretos, palco desta análise, e sua íntima relação com o território em que habitam. Na segunda seção serão tratados dos conceitos teóricos basilares necessários à compreensão deste estudo. Na terceira seção serão demonstrados os resultados obtidos com a aplicação do DRP (Diagnóstico Rural Participativo) na comunidade além de alguns relatos capturados em entrevistas. 


\section{QUILOMBOLAS NO PARANÁ E PALMITAL DOS PRETOS: ASPECTOS SOCIOCULTURAIS}

Evidentemente que o termo quilombola há muito superou a conceituação do Conselho Ultramarino de 1740, endereçada ao Rei de Portugal, onde quilombo era retratado como "Toda habitação de negros fugidos que passem de cinco, em parte despovoada, ainda que não tenham ranchos levantados nem se achem pilões neles." (SCHMITT, 2002, p. 2).

O termo "quilombola" tem sofrido resignificações ao longo dos anos, sobretudo após a constituição de 1988. Hoje, “A partir das formas de organização é possível perceber que a maioria das comunidades não provém de antigos quilombos em que se agrupavam escravos fugitivos." (MARQUES, 2013, p. 42).

De acordo com o manifesto elaborado pelo CONAQ - Coordenação Nacional de Quilombos: "As comunidades quilombolas são grupos étnicos, predominantemente constituídos pela população negra rural ou urbana (...)." (CONAQ, 2012, p. 1). Nota-se que, ao caracterizar como "predominantemente" a presença da população negra, o CONAQ atesta a natural miscigenação destas comunidades.

Atualmente, o conceito de comunidade quilombola possui múltiplas representações. As comunidades quilombolas são acima de tudo grupos sociais minoritários, majoritariamente camponeses, em constante luta pelos direitos sociais que via de regra lhes são negados. Não são grupos homogêneos no que tange a cor de pele ou modo de vida, mas são uníssonos na segregação territorial, exclusão e invisibilidade social.

A luta destas comunidades tem sido ora potencializada ora enfraquecida ao longo do tempo republicano, sofrendo ressignificações conforme as políticas de reconhecimento dos direitos das populações tradicionais sobre seus territórios, apoiada ou impulsionada pelos movimentos sociais conforme o contexto político em que se encontram.

No Paraná, a presença da população afrodescendente tem sido negligenciada historicamente. A máxima de que o Paraná é um estado europeizado macula o reconhecimento da presença e atuação do negro no estado, bem como das comunidades quilombolas existentes. A histórica invisibilidade dos quilombolas no estado é majorada pelo fato de que estes se agrupam no meio rural em pequenas e esparsas comunidades. Deve-se considerar ainda que:

A colonização da região Sul atendeu aos interesses das elites intelectuais e políticas de implantar um povoamento com populações tidas como racialmente superiores e provenientes de áreas tidas como mais desenvolvidas. Com o intuito de tornar o País "racialmente mais branco", propiciou condições favoráveis aos imigrantes e com elas a reprodução das desigualdades instauradas no período escravista, confirmando, assim, as teorias raciais em vigor. (LEITE, 2008, p. 967).

Hoje, reconhece-se o Paraná como um estado multiétnico, tendo, inclusive, a população afrodescendente mais expressiva dos estados do sul do país. O Paraná possui cerca de $24 \%$ de sua população composta por negros (GOMES JUNIOR; SILVA; COSTA 
BRACARENSE, 2008). Além do grande número de pessoas que se auto definem como negras; ao todo são 34 comunidades quilombolas espalhadas pelo estado, sendo todas elas no meio rural e instaladas em locais longínquos.

(...) tanto a quantidade quanto a localização da maioria das comunidades negras tradicionais atestam a marginalização a que foi submetido o povo negro, haja vista o fato de que as comunidades estão, na sua maioria, instaladas nas regiões de mais baixo IDH do Paraná (...), bastante distantes das sedes dos municípios, longe da atenção do poder público e carentes de políticas que atendam às suas necessidades. Assinale-se que isso não ocorre apenas nessa unidade da federação. (GOMES JUNIOR; SILVA; COSTA BRACARENSE, 2008, p. 19).

Na representação da Figura 1 é possível visualizar onde estão agrupadas as comunidades quilombolas do Paraná. A maior parte delas concentra-se na porção centro-leste do estado.

Figura 1 - Representação cartográfica das comunidades quilombolas no Paraná

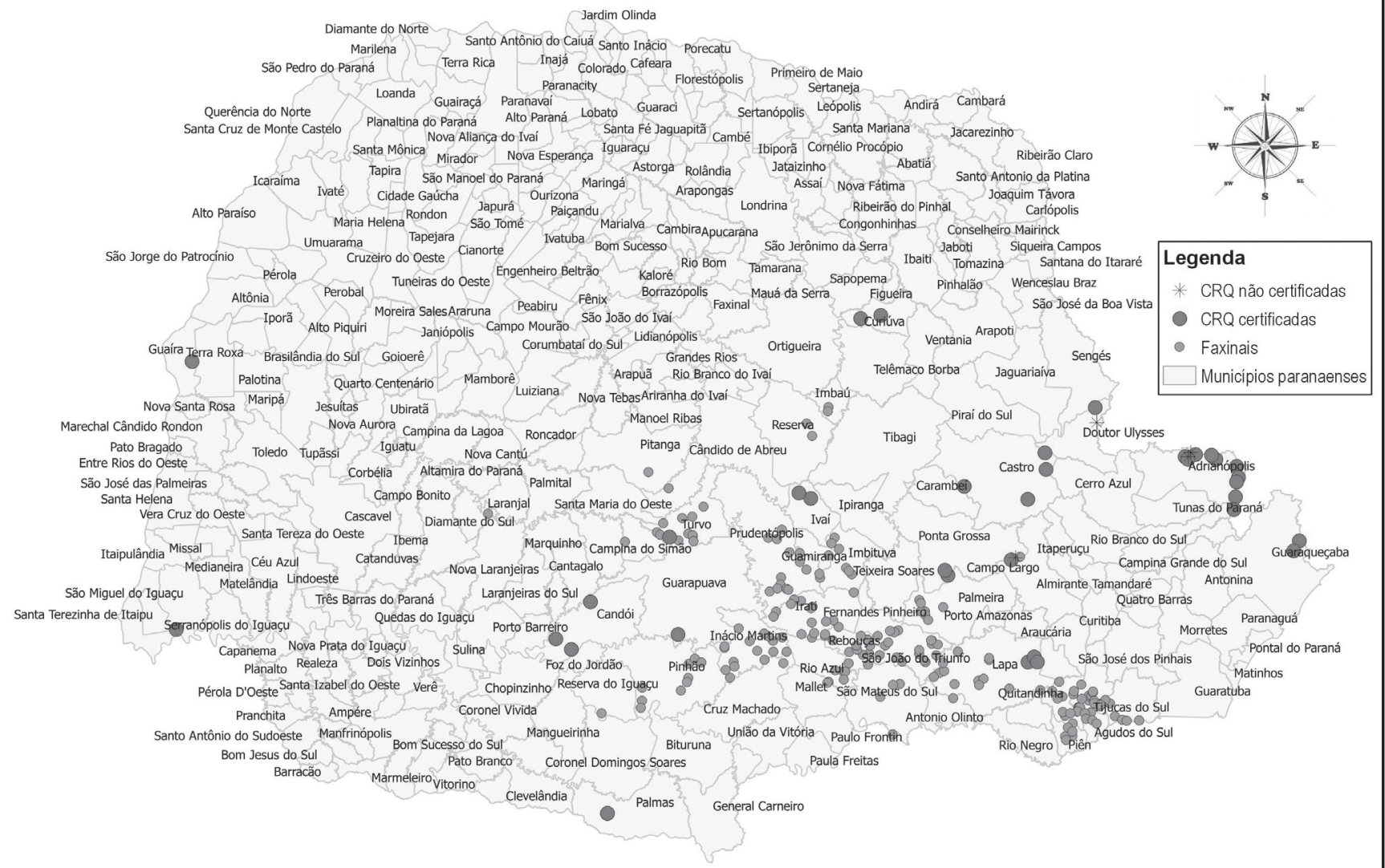

Fonte: ITCG (2013). Organizado pelo autor.

As comunidades quilombolas apresentadas na figura só foram descerradas com o trabalho do Grupo Clóvis Moura. O Grupo Clóvis Moura foi estruturado pelo Governo do Estado do Paraná em 2005 com o objetivo de conhecer as comunidades quilombolas no estado. O Grupo funcionou de 2005 a 2010 e é um divisor de águas na luta pelo 
reconhecimento da importância do afrodescendente para o Estado e no conhecimento das comunidades quilombolas.

Marques (2008) aponta que a data de publicação do reconhecimento das 34 comunidades quilombolas do Estado pela Fundação Palmares ${ }^{1}$ se deu após a efetivação do Grupo Clóvis Moura o que reforça a importância do grupo para a história do povo negro do Estado.

A comunidade quilombola de Palmital dos Pretos é uma das que teve seu reconhecimento tracionado pelo Grupo de trabalho Clóvis Moura. A comunidade teve seu reconhecimento em junho de 2006, entretanto, a existência da mesma remonta a meados de 1850. (CELINSKI, 2010).

Durante o período de opressão, os escravos fugiram das fazendas de imigrantes europeus que chegaram entre 1850 e 1950 e se instalaram na região próxima à Estrada do Cerne e de Palmeira - buscando um local seguro. Os fugitivos, e mais tarde os exescravos, se instalaram numa região afastada 83 quilômetros da sede do município de Campo Largo (...). (CELINSKI, 2010, p. 28).

A comunidade de Palmital dos Pretos, mesmo sendo bastante antiga, ainda aguarda a regularização da posse de suas terras. Embora seu reconhecimento tenha ocorrido por parte da Fundação Palmares em 2006, ainda há a necessidade do INCRA (Instituto Nacional de Colonização e Reforma Agrária) regulamentar e efetivar a demarcação das terras. (BRASIL, 2003) Esta morosidade tem afetado o modo de vida da comunidade.

Atualmente, na comunidade de Palmital os chefes das famílias, com pouca ou nenhuma terra para plantar, acabam tendo que trabalhar em empresas madeireiras da região. As mulheres tomam conta da casa e do trabalho agrícola (aquelas que dispõem de terra) e algumas produzem pães e biscoitos na cozinha comunitária, cuja produção circula apenas na própria comunidade.

Os negros, como integrantes de um segmento desvalorizado e desqualificado, ficam a mercê da sazonalidade das ofertas de trabalho nos setores em expansão na construção civil, como bóias-frias, safristas ou posseiros, e principalmente na economia informal. (LEITE, 2008, p. 968).

Contudo o avanço significativo observado nas últimas décadas no reconhecimento dos direitos das comunidades quilombolas, em que pesa a falta de celeridade no processo, a trajetória de lutas está longe de acabar. O decreto $\mathrm{n}^{\circ} .4887$ que estabelece parâmetros para a regularização fundiária das comunidades quilombolas só passou a vigorar em 2003, ou seja, quinze anos após a constituição de 1988 que já trazia em seu artigo 68 tais direitos nos seguintes termos: "Aos remanescentes das comunidades dos quilombos que estejam ocupando suas terras é reconhecida a propriedade definitiva, devendo o Estado emitir-lhes os títulos respectivos." (BRASIL, 1988).

\footnotetext{
${ }^{1}$ Criada em 1988, a Fundação Cultural Palmares é uma instituição pública vinculada ao Ministério da Cultura que tem a finalidade de promover e preservar a cultura afro-brasileira. Preocupada com a igualdade racial e com a valorização das manifestações de matriz africana, a Palmares formula e implanta políticas públicas que potencializam a participação da população negra brasileira nos processos de desenvolvimento do País. (PALMARES, 2010)
} 
As reivindicações dos direitos territoriais dos grupos étnicos implica a vivência do conflito social em uma sociedade patrimonialista na qual a terra é mercadoria regulada na esfera das relações econômicas de compra e venda. Essa sociedade oblitera direitos associados às formas de viver e interagir que envolvem outras dinâmicas de organização. (MARQUES, 2013, p. 52).

Nas incursões realizadas na comunidade percebe-se que a preservação da cultura quilombola está intrinsecamente atrelada à história da relação da comunidade com a terra, isto é, relação produtiva e afetiva com seu lugar. A relação com o território em termos de regime de uso comum dos bens naturais historicamente ocorreu de maneira diferenciada: recebido como doação pelos serviços prestados aos jesuítas, o grupo de negros responsáveis pelas terras passariam a se apropriar produtivamente destas sob o regime de uso comum.

Com a institucionalização da lei das terras de 1850, na qual prevê apenas duas modalidades para se ter terra, por herança ou por compra, os descendentes de escravos estrategicamente viram-se obrigados a ceder parcelas de seu território para aquisição de glebas de terra mediante compra, fazendo com que o território fosse cada vez mais diminuído. Com o passar dos anos, os quilombolas foram perdendo parcelas importantes de seu território para os grandes fazendeiros, de maneira a dividir o território e descaracterizá-lo daquilo que originalmente compunha a área jesuíta.

Atualmente, a organização espacial de seu território figura com áreas de terras diminutas, nas quais poucas famílias trabalham a agricultura, além disso, apresentam um quadro de aumento demográfico, levando o jovem quilombola a buscar outras formas de subsistência fora da comunidade. O que era tido antes como uma prática tradicional comum, ou seja, o uso coletivo dos recursos naturais, hoje é parcialmente substituído pela propriedade privada da terra e pela oferta de mão de obra daqueles que não tem ou possuem pouca terra.

Nesta esteira, particularmente no caso quilombola, a territorialidade deve ser compreendida através dos conceitos mais abrangentes e a partir de duas dimensões basilares, que segundo Haesbaert podem ocorrer concomitantemente, e são:

(...), uma dimensão simbólica, cultural, por meio de uma identidade territorial atribuída pelos grupos sociais, como forma de controle simbólico sobre o espaço onde vivem (sendo também, portanto, uma forma de apropriação), e uma dimensão mais concreta, de caráter político-disciplinar: a apropriação e ordenação do espaço como forma de domínio e disciplinarização dos indivíduos. (HAESBAERT, 2004, p. 42).

A identidade quilombola, por exemplo, decorre das duas dimensões. A afirmação da identidade quilombola é facilitadora na luta pela posse legal da terra (dimensão político-disciplinar), ao passo que a apropriação da terra e por consequência o trabalho agrícola, são pressupostos para a manutenção e afirmação desta identidade. Uma remete à outra, além do que:

Em tal situação de desigualdade, os grupos minoritários passam a valorar positivamente seus traços culturais diacríticos e suas relações coletivas como forma 
de ajustar-se às pressões sofridas, e é neste contexto social que constroem sua relação com a terra, tornando-a um território impregnado de significações relacionadas à resistência cultural. Não é qualquer terra, mas a terra na qual mantiveram alguma autonomia cultural, social e, consequentemente, a autoestima. Siglia Dória salienta que a identidade de grupos rurais negros se constrói sempre numa correlação profunda com o seu território e é precisamente esta relação que cria e informa o seu direito à terra. (SCHMITT, 2002, p.5).

No caso da comunidade de Palmital dos Pretos, o sufocamento promovido pela morosidade do poder público em lhes legitimar a posse de suas terras e também a pressão dos grandes proprietários fundiários que margeiam suas propriedades com enormes plantações de pinus, acentuam ainda mais a busca por uma identidade que lhes permita praticar sua cultura livremente, em coexistência com a diversidade socioterritorial da região onde se insere a comunidade.

Em que pese à perda de parcelas de seus territórios e a rude transformação das práticas produtivas, a comunidade quilombola continua a reproduzir sua cultura, sobretudo no que tange aos aspectos imateriais (religiosidade, hábitos alimentares, saberes medicinais, paisagísticos, etc.).

De tudo retro exposto, percebe-se que a comunidade de Palmital dos Pretos ainda vive o histórico ostracismo a que esteve fadada a população afrodescendente no Estado do Paraná. A trajetória em busca dos seus direitos fundamentais parece avançar em descompasso com o progresso econômico e benfeitorias no campo social visualizadas no país nos últimos anos. Destarte, os hábitos materiais que compõem a cultura dos remanescentes demonstram sinais de enfraquecimento, ocupando lugar apenas na memória destes, corroborando com a importância da política de regulamentação fundiária para garantir o acesso às terras anteriormente partilhadas e sua reprodução cultural em todas as suas dimensões e assim, permitindo com que essa coletividade resista às disputas e conflitos entre outros atores, tais como o estado, iniciativa privada, multinacionais, fazendeiros, etc.

\section{CULTURA, IDENTIDADE, PATRIMÔNIO CULTURAL (I)MATERIAL E MEMÓRIA}

O Decreto Federal n ${ }^{\circ} .4887$ que regulamenta o art. 68 do ADCT (Ato das Disposições Constitucionais Transitórias), trata-se de uma legislação moderna, especialmente por elencar a autoatribuição como um dos critérios para se caracterizar uma comunidade quilombola. $\mathrm{O}$ critério da autoatribuição se amolda a atual visão da antropologia. (LEITE, 2008).

Outro aspecto pertinente do decreto em comento é a citação de que assegurando-se a posse das terras ocupadas pelos quilombolas, asseguram-se também a reprodução física, econômica e sobretudo cultural destas comunidades. "Art. $2^{\circ} \S 2$ ㅇão terras ocupadas por remanescentes das comunidades dos quilombos as utilizadas para a garantia de sua reprodução física, social, econômica e cultural." (BRASIL, 2003). 
Estabelecendo-se o contraditório, têm-se a ação direta de inconstitucionalidade (ADI n. 3239) impetrada pelo partido político Democratas (DEM) tramitando no Supremo Tribunal Federal. A ADI contesta os critérios estabelecidos para a demarcação das terras, pois considera frágil o critério da auto-atribuição, bem como, o uso do laudo antropológico neste julgamento.

Entretanto, o princípio da legalidade não pode cegar-se perante aspectos que margeiam uma definição de posse fundiária desta natureza. Apenas a análise literal dos dispositivos legais não constituem subsídios robustos capazes de formular um juízo cabal, é necessário uma análise acurada, considerando inclusive a cultura praticada por estes povos e sua importância na constituição do Estado-nação brasileiro.

Os laudos antropológicos são extremamente detalhistas e trazem consigo pujante análise da história de estruturação destas comunidades, suas relações familiares, seus hábitos cotidianos, enfim, suas culturas. Reconhece-se o posicionamento do partido em tela, entretanto, esta não reveste-se de argumentação sólida, especialmente por desconsiderar a fragilidade a que expõe a cultura destes povos.

Outrossim, a cultura que se pretende tutelar nestas comunidades e que deve ser considerada pelo poder público no tratamento das áreas em litígio, assume a conotação mais abrangente possível, sendo esta, muito bem expressa nas palavras da feminista McDowel:

Cultura é um conjunto de ideias, hábitos e crenças que dá forma às ações das pessoas e à sua produção de artefatos materiais, incluindo paisagem e ambiente construído. A cultura é socialmente definida e socialmente determinada. Ideias culturais são expressas nas vidas dos grupos sociais, que articulam, expressam e contestam esses conjuntos de ideias e valores, que são eles próprios específicos no tempo e no espaço. (McDOWEL, 1996, p. 161).

Atualmente, há certa dificuldade em se caracterizar e situar a cultura quilombola, que pode ser explicada pelos vários tensionamentos dirigidos ao processo de aculturação ${ }^{2}$ daquelas famílias. Além do processo de aculturação espontâneo que ocorre por conta do contato com outras culturas, tem-se na gênese de sua formação a tentativa de aculturação forçada que reflete na atual situação desta:

A situação de uma aculturação organizada, mas forçada, em benefício de um só grupo, como no caso da escravidão ou da colonização. Há, então, vontade de modificar em curto prazo a cultura do grupo dominado para submetê-lo aos interesses do grupo dominante. (CUCHE, 1999, p. 129).

Hoje, paralelo ao multifacetado processo de incorporação de culturas, paira sobre a comunidade a necessidade de resistir ao processo de aculturação que projeta sobre eles características que não são deles. Esta resistência é parte do processo que legitima a posse da terra aos quilombolas e possibilita o acesso a outros serviços que lhes são concedidos através da construção e manutenção desta identidade.

\footnotetext{
2"A palavra não designa uma pura e simples "deculturação". Em "aculturação", o prefixo "a" não significa privação; ele vem
} do etimologicamente do latim ad e indica um movimento de aproximação." (CUCHE, 1999, p. 114). 
Entretanto, cabe salientar que a identidade quilombola não se estrutura apenas da necessidade de lutar pela terra, embora seja este o principal elemento detectado na comunidade de Palmital dos Pretos. Apoderando-se do pensamento dos defensores do conceito subjetivo de identidade, esta não poderia ser reduzida à sua dimensão atributiva, ela não é definitiva, tampouco estática. (CUCHE, 1999).

Assim, na esteira de Barth, podemos pensar as identidades não como sendo fixas, mas, tomando as palavras de Boaventura Souza Santos, como identificações em curso, integrantes do processo histórico da modernidade, no qual concorrem velhos e novos processos de recontextualização e de particularização das identidades. (SCHMITT; TURATTI; CARVALHO, 2002, p.5, 2002, p.5).

A identidade quilombola, hoje, passa pela turbulência dos descentramentos de identidades típicos do mundo pós-moderno. (HALL, 1997). A comunidade está fadada à nova articulação entre global e local, onde os efeitos da globalização interagem com a necessidade de se reafirmar seus traços culturais e suas identidades, formando na comunidade um hibridismo para ambos os aspectos.

Há que se considerar que a identidade quilombola se constrói também pela diferença. "A identidade é uma construção que se elabora em uma relação que opõe um grupo aos outros grupos com os quais está em contato." (CUCHE, p. 182, 1999). Esta diferença, no caso quilombola denota subalternidade, "Boaventura S. Santos, ao relacionar identidade e questões de poder, nos lembra que quem é obrigado a reivindicar uma identidade encontra-se necessariamente em posição de carência e subordinação." (SCHMITT; TURATTI; CARVALHO, 2002, p.5, 2002, p.5).

Esta posição de inferioridade imposta pela sociedade de classes, e a existência de um hibridismo de identidades e culturas, não inviabilizam a percepção de um verdadeiro patrimônio cultural a ser observado, catalogado e relatado. O patrimônio cultural quilombola se faz presente tanto no plano material (geossímbolos) como no plano imaterial (patrimônio intangível):

Um geossímbolo pode ser definido como um lugar, um itinerário, uma extensão que, por razões religiosas, políticas ou culturais, aos olhos de certas pessoas e grupos étnicos assume uma dimensão simbólica que os fortalece em sua identidade. (BONNEMAISON, 2003, p. 109).

A transição entre o velho e o novo modifica naturalmente os geossímbolos e também os hábitos das famílias quilombolas. Esta transição reforça a necessidade de se aprofundar os conhecimentos entorno do patrimônio cultural quilombola, tanto em suas origens quanto no contexto contemporâneo, a fim de estimular a conservação deste.

De acordo com Oliven, "o termo "patrimônio" - em inglês, heritage - refere-se a algo que herdamos e que, por conseguinte, deve ser protegido" (2003, p. 77). Ocorre que, não se protege o que não se conhece, e conhecer o patrimônio imaterial de uma comunidade tradicional não é uma das tarefas mais fáceis, demanda, acima de tudo, aprofundada interação com a comunidade. 
O patrimônio intangível, como etimologicamente se propõe não se trata de algo palpável, logo é de difícil mensuração, especialmente por se tratar no Brasil de uma categoria recente de patrimônio. O patrimônio imaterial, no Brasil, passou a ser considerado somente em meados de 1930, através de proposta do poeta Mário de Andrade ao governo federal. A proposta do modernista não foi bem recepcionada pelo então ministro da Educação e Cultura, Gustavo Capanema. (ABREU, 2003).

Da mesma forma como ocorreu com o reconhecimento dos direitos quilombolas, somente com a Constituição Federal de 1988 esta categoria de patrimônio foi considerada no Brasil. Ainda assim, somente doze anos após a CF de 1988 a categoria foi efetivamente regulamentada, através do Decreto $\mathrm{n}^{\circ}$. 3551 de 4 de agosto de 2000. (ABREU, 2003).

Nessa nova categoria estão lugares, festas, religiões, formas de medicina popular, música, dança, culinária, técnica, etc. Como sugere o próprio termo, a ênfase recai menos nos aspectos materiais e mais nos aspectos ideais e valorativos dessas formas de vida. Diferentemente das concepções tradicionais, não se propõe o tombamento dos bens listados nesse patrimônio. A proposta é no sentido de "registrar" essas práticas e representações e de fazer um acompanhamento para verificar a permanência e suas transformações. (GONÇALVES, 2003, p.24).

As transformações naturais por que passa a comunidade não inibe que seus saberes e práticas tradicionais sejam conservados. No quilombola é perceptível uma riqueza imaterial em todos os sentidos, que vai desde os cuidados com a saúde, às estratégias próprias de conservar e preparar alimentos, festas tradicionais, algumas expressões de linguagem, a cantoria das mulheres, etc.

Além da riqueza imaterial da comunidade, em uma das visitas realizadas, foi encontrado um pilão, que segundo seu dono possui mais de 250 anos. O pilão reforça a presença dos geossímbolos (patrimônio material) interagindo com os já citados patrimônios imateriais presentes naquela comunidade. É testemunha também de processos de miscigenação cultural (a cultura indígena). O território quilombola do Palmital é pura miscigenação (cabocla e negra) em sua origem.

Como já retratado, os geossímbolos da comunidade quilombola sofreram as naturais reconfigurações, o patrimônio cultural nem sempre é manifestado para além do plano da inconsciência, mas a memória é vívida dentre aquelas famílias e constantemente é compartilhada entre eles e também fora da comunidade.

(...) a memória é um fenômeno construído social e individualmente, quando se trata da memória herdada, podemos dizer há uma ligação fenomenológica muito estreita entre memória e o sentimento de identidade. Aqui, o sentimento de identidade está sendo tomado no seu sentido mais superficial, mas que nos basta no momento, que é o sentido da imagem de si, para si e para outros. (PLLAK apud MARQUES, 2008, p. $54)$. 
Figura 2 - Um dos pilões encontrados na comunidade de Palmital dos Pretos, Campo Largo, PR

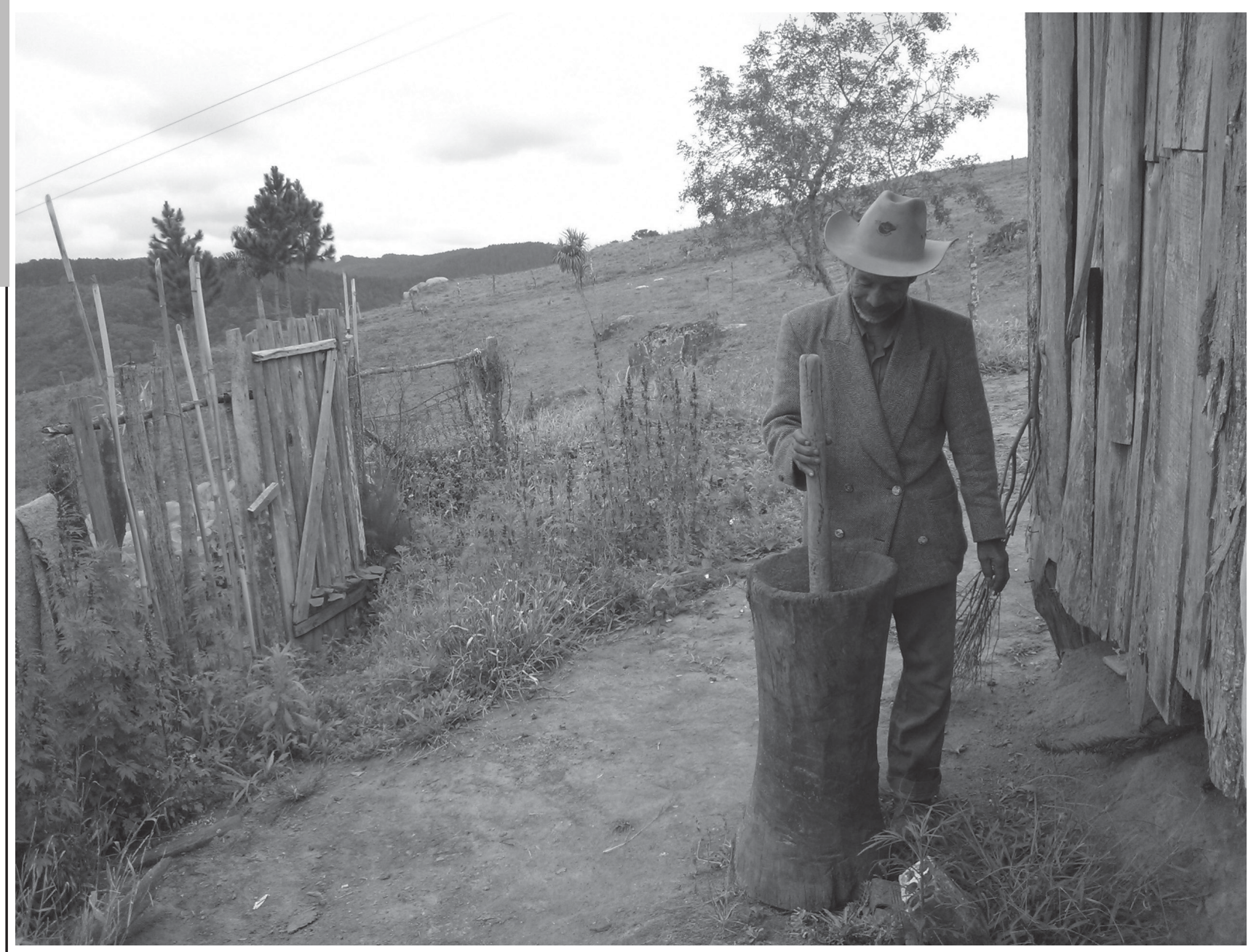

Fonte: Grupo de Pesquisa Interconexões, 2013.

A memória, neste caso, referencia o projeto quilombola no tempo e no espaço. As lembranças da luta de seus antepassados por um chão ermo, bem como as recordações trazidas das antigas festas, da forma como preparavam alimentos e de seus cotidianos como um todo, reforçam e resgatam suas identidades enquanto quilombolas.

Ademais, os únicos registros remanescentes da cosmografia ${ }^{3}$ do grupo, não raras vezes, estão presentes apenas em suas memórias. Arruti (1998) citado por Little (2002) atesta com base em estudos passados, que a memória ocupa papel de protagonista no embate jurídico em prol da terra quilombola: "sua memória tornou-se tão importante quanto os documentos escritos que antes, no confronto com representantes dos poderes públicos, tinham o total privilégio." (ARRUTI, 1998, p.26 apud LITTLE, 2002, p.12).

Desta importância emerge a necessidade de se relatar e conservar os enunciados trazidos pela memória dos povos quilombolas, quiçá, seja este o único caminho para se

\footnotetext{
${ }^{3}$ (...) conceito de cosmografia (LITTLE, 2001), definido como os saberes ambientais, ideologias e identidades - coletivamente criados e historicamente situados - que um grupo social utiliza para estabelecer e manter seu território. A cosmografia de um grupo inclui seu regime de propriedade, os vínculos afetivos que mantém com seu território específico, a história da sua ocupação guardada na memória coletiva, o uso social que dá ao território e as formas de defesa dele. (LITTLE, 2002, p.4).
} 
materializar os direitos sociais aos remanescentes. Sendo necessário também o reconhecimento e a correta valoração de suas práticas enquanto uma cultura que contribuiu significativamente para a estruturação do Estado e do País.

\section{RESULTADOS}

As investigações junto à comunidade quilombola de Palmital dos Pretos iniciaram-se pela líder, D. Elenita, nascida na comunidade, assim como seu marido e todos os seus filhos. Foi ela quem acompanhou e facilitou o acesso às famílias que vivem na comunidade. Nas primeiras incursões de cunho meramente exploratório, a líder reunia as pessoas da comunidade na cozinha comunitária ${ }^{4}$, geralmente os mais idosos e mulheres, e apresentava o grupo de pesquisa a eles, inspirando-lhes confiança em responder os questionamentos vindouros.

Nos primeiros contatos houve certa animosidade por parte dos remanescentes. Percebeu-se no discurso deles que pesquisas anteriores realizadas na comunidade fizeram com que os quilombolas se sentissem apenas usados, pois inúmeras vezes reclamavam não ter acesso ao resultado das pesquisas.

Quando solicitado a eles a permissão para fotografar os encontros na cozinha, uma das mulheres presentes bradou em meio as outras sua insatisfação, nos seguintes termos: "Vocês querem tirar fotos dos pretos pra pôr os pretos lá na internet, eu não quero tirar foto nenhuma". Esta aspereza apresentada pelas mulheres, além de acentuar a necessidade de estreitar os laços de confiança e comprometimento com os sujeitos da pesquisa, endossou ainda mais a pretensão que se tinha de utilizar o DRP (Diagnóstico Rural Participativo) no curso da investigação. O DRP faz com que a população investigada tenha subsídio para sua autogestão, retornando, incontinenti, os resultados à comunidade. (VERDEJO, 2006).

O diagnóstico se mostra bastante pertinente, especialmente no que tange à preservação da identidade cultural da comunidade quilombola, tendo em vista que a partir do DRP é possível que a comunidade perceba que a valorização de suas identidades enquanto comunidade quilombola transpassa a questão fundiária, em níveis de importância.

O DRP pretende desenvolver processos de pesquisa a partir das condições e possibilidades dos participantes, baseando-se nos seus próprios conceitos e critérios de explicação. Em vez de confrontar as pessoas com uma lista de perguntas previamente formuladas, a ideia é que os próprios participantes analisem a sua situação e valorizem diferentes opções para melhorá-la. (VERDEJO, 2006 p. 6).

O processo de reflexão iniciado com o uso do DRP mostrou-se um diferencial metodológico. Ao invés de tão somente utilizar-se da comunidade para a pesquisa, foi

\footnotetext{
${ }^{4} \mathrm{Na}$ comunidade há uma cozinha comunitária construída e aparelhada com apoio da EMATER e órgãos do Governo Federal e Municipal de Campo Largo. Na cozinha são produzidos pães, bolos e biscoitos caseiros, cuja venda se restringe à própria comunidade por problemas de operacionalização logística.
} 
estabelecido, de imediato uma relação de troca onde desde o início a comunidade está acompanhando os resultados do trabalho.

Além de facilitar a demonstração de resultados parciais e incentivar o desenvolvimento da comunidade pesquisada, o DRP contribui para que se possa conhecer detalhadamente suas características, considerando que as informações são obtidas de forma lúdica, diferentemente dos métodos tradicionais de investigação, que poderiam ser inibidores ou condicionar o discurso dos pesquisados, diante da animosidade ora apresentada.

Dentre as ferramentas do DRP, foram aplicados a matriz de organização comunitária, baseada na dinâmica FOFA (Fortalezas, Oportunidades, Fraquezas e Ameaças) e o diagrama de Venn (VERDEJO, 2006). Na data da aplicação dos diagnósticos estavam presentes na cozinha comunitária 7 (sete) mulheres da comunidade, as quais, devido à constante interação com os assuntos da comunidade, são tidas como lideranças de apoio à D. Elenita.

A dinâmica FOFA oportunizou a reflexão da comunidade sobre suas Fraquezas, Oportunidades, Fortalezas e Ameaças. As respostas obtidas com na aplicação da dinâmica FOFA, foram tabuladas e organizadas em uma matriz de priorização dos problemas, onde as principais debilidades da comunidade são elencadas em qualquer ordem e a partir disto os investigados apontaram para os mais e menos importantes. Na dinâmica FOFA, foram elencadas os seguintes tópicos:

Figura 3 - Resultados da aplicação FOFA na comunidade Palmital dos Pretos, Campo Largo - PR

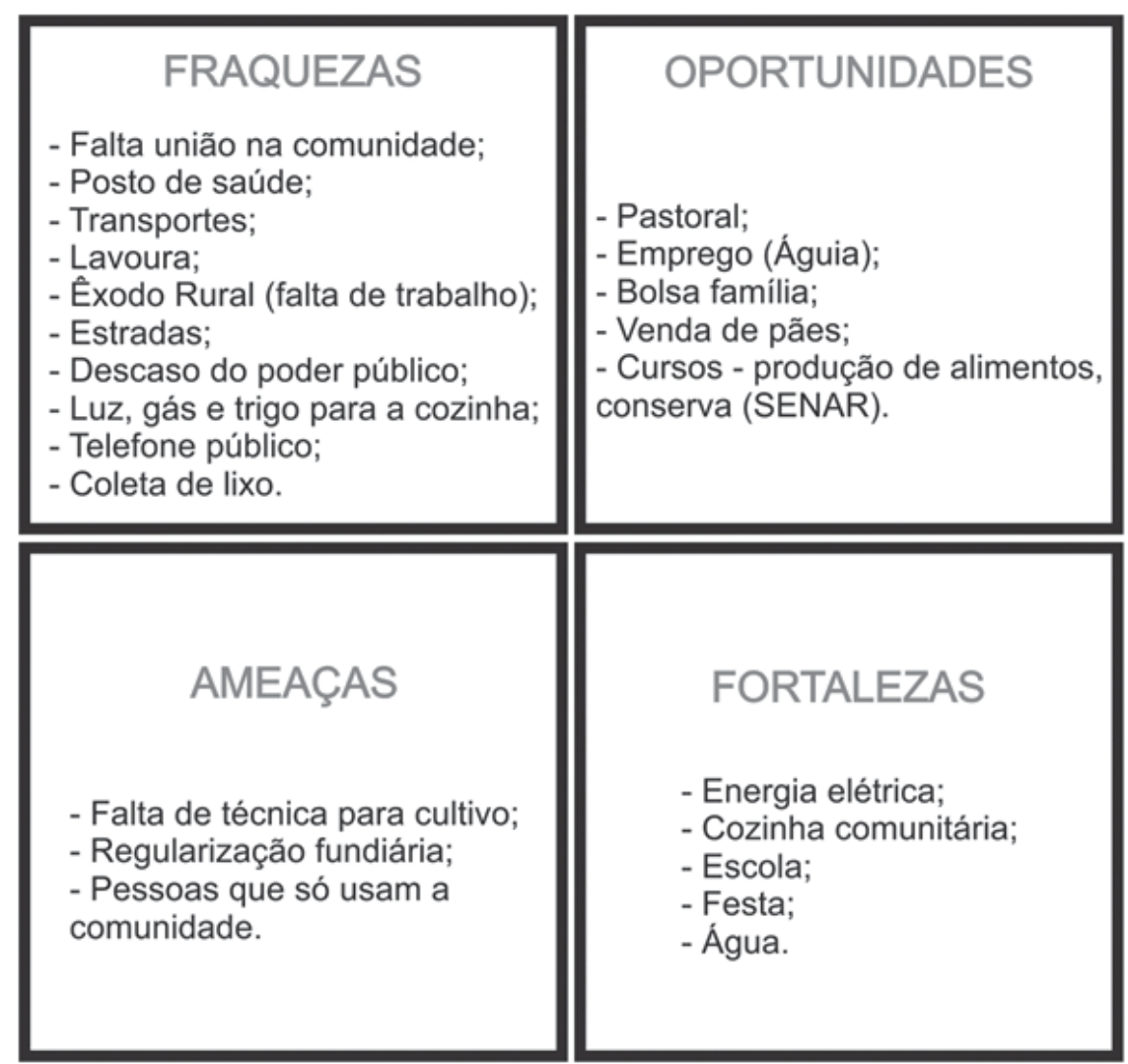

Fonte: o autor, 2013. 
As fraquezas apontadas pelas mulheres da comunidade foram organizadas em outra matriz, onde elas foram hierarquizadas de acordo com os apontamentos das participantes da dinâmica, a saber:

Quadro 1 - Matriz de priorização dos problemas identificados na comunidade Palmital dos Pretos, Campo Largo - PR

\begin{tabular}{|c|c|}
\hline Problema & Quantidade de apontamentos \\
\hline Saúde & 1 \\
\hline Desunião & - \\
\hline Transporte/estradas & 1 \\
\hline Lavoura/pragas & - \\
\hline Prefeitura/descaso & - \\
\hline Regularização de terras & 5 \\
\hline
\end{tabular}

Fonte: o autor, 2013.

A maioria dos tópicos que haviam sido apontados pelas lideranças da comunidade quilombola como sendo fraqueza e ameaça possui conexão direta com o território em suas diferentes acepções. Daí emerge o principal empecilho na preservação do patrimônio cultural quilombola, haja vista o território ser a base do modo de vida da comunidade.

A ausência de terras agricultáveis e insumos, a morosidade da regularização fundiária, e outros fatores, convergem para a mudança dos hábitos dos quilombolas, que dia-a-dia afastam-se do labor na terra e tornam-se dependentes de outras formas de obtenção de renda. Esta falta de terras para o plantio obriga os mais jovens a deixar a comunidade em busca de empregos no meio urbano. Êxodo este pernicioso, considerando que na maior parte das casas visitadas, os filhos dos remanescentes estão trabalhando no meio urbano em empregos de remuneração baixa e em inúmeros casos acabam voltando pra comunidade, ingressando num ciclo de idas e vindas. O êxodo rural propulsado pela ausência de terras agricultáveis, enfraquece a coesão da comunidade e resulta no que foi apontado como "falta de união" durante a execução da matriz FOFA.

Aqueles que não migram para o espaço urbano acabam por ter poucas escolhas, geralmente trabalham em empresas madeireiras da região. Seja nas inúmeras plantações de pinus ou no parque industrial para produção de madeiras, os trabalhadores passam a semana toda longe de suas casas, pernoitando em alojamentos e retornando apenas aos finais de semana.

(...) Nas áreas rurais, a desinformação, o esgotamento das terras, o aumento demográfico e principalmente a chegada avassaladora das agroindústrias vão ampliando, ao longo dos anos, os níveis de conflito, o êxodo e a desagregação dos grupos familiares, e, com eles, também os estigmas e as intolerâncias étnicas. (LEITE, 2008, p.968).

A ausência da terra inviabiliza seu modo de vida e de organização, tanto do ponto de vista econômico, quanto no aspecto da sobrevivência de elementos identitários essenciais à manutenção do modelo civilizatório de que são originárias essas pessoas. (JÚNIOR, 2008, p.18). 
Uma vez conhecidos e elencados os principais problemas da comunidade, partiuse para a aplicação do diagrama de Venn, visando aferir a acessibilidade das famílias aos recursos (fortalezas-oportunidades) públicos ou privados. (VERDEJO, 2006).

Para desenvolver-se o diagrama de Venn, coloca-se a comunidade no centro de um círculo, e desenham-se vários outros círculos maiores em volta dela. No círculo mais distante inserem-se as instituições/organizações apontadas pelos participantes como distantes, não apenas em termos territoriais, mas principalmente na abertura ao diálogo e apoio. Consequentemente, nos círculos mais pertos estarão as instituições/organizações de maior interação com a comunidade. (VERDEJO, 2006).

Figura 4 - Resultados apresentados no Diagrama de Venn na comunidade Palmital dos Pretos, Campo Largo - PR

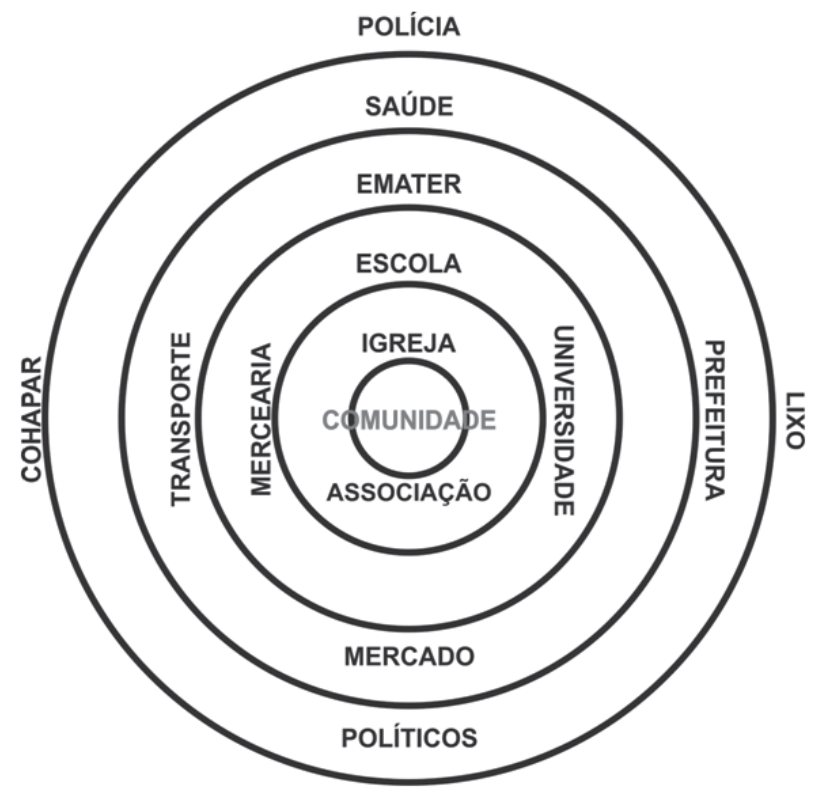

Fonte: o autor,2013.

O poder público com jurisdição sobre a comunidade é a prefeitura municipal de Campo Largo, no entanto, esta, juntamente com a Companhia de Habitação do Paraná (COHAPAR), são consideradas pelas famílias como distantes e ineficazes no apoio à comunidade. Tão longes quanto, estão os serviços de coleta de lixo, saúde e segurança pública.

Com o diagrama de Venn abstraem-se inúmeras reflexões no que tange ao apoio e interação da comunidade com órgãos do poder público e privado, oportunizando aos quilombolas uma auto-gestão direcionada. Assim, o DRP ratifica sua importância enquanto instrumento metodológico fornecendo resultados satisfatórios para pesquisador e pesquisados.

Dando sequência na investigação, foram realizadas entrevistas com algumas famílias, as quais foram iniciadas pela líder da comunidade, a partir disto, através da técnica do snowball (bola de neve), solicitou-se a ela que indicasse outra pessoa a ser entrevistada. (BALDIN; MUNHOZ, 2011). 
Durante as entrevistas, as pessoas inquiridas reforçaram a proximidade da igreja apontada no diagrama de Venn. Visualizou-se em boa parte das casas visitadas imagens de santo, terços e velas em pequenos altares de madeira, geralmente na sala de estar das residências.

A religiosidade é um dos alicerces da comunidade. A maior parte das famílias entrevistadas é católica e frequenta a missa aos sábados de quinze em quinze dias, entretanto, há algumas famílias evangélicas frequentadoras da igreja Congregação Cristã do Brasil, com sede instalada na entrada da comunidade.

A igreja evangélica é considerada pela comunidade como mais próxima do que a católica, mesmo com número menos expressivo de frequentadores. Isto deve-se ao fato da igreja evangélica fornecer um apoio no campo social mais incisivo às famílias, conforme observou-se no discurso das mulheres locais, ilustrado no seguinte recorte: "A casa dela" (se referindo a casa de outra mulher) "foi feita pela igreja, foi a igreja dela que deu tudo pra ela" (E.M., feminino)

A igreja católica é considerada mais distante, pois, as visitas do padre se dão a cada quinze dias e, conforme relatos das mulheres locais, o mesmo inibe a promoção de festas na comunidade sem que haja a contrapartida da lucratividade. $O$ acesso às instalações da igreja, lugar onde as famílias costumeiramente utilizavam para as mais variadas formas de reuniões sociais, encontra-se inviabilizado pelo pároco, o qual não cede mais as chaves para tais práticas. Os relatos corroboram a insatisfação: "Antes nóis fazia festa de tudo quanto é santo, nóis abria a bíblia e achava os santo e já fazia uma festa com aquele nome, hoje não fazemos mais, o padre quer que a gente cobre" (P.E., masculino). "Em janeiro nóis fazemo a nossa festa, vem gente de toda parte e não cobramo um centavo pra da de come tudo aquela gentarada, estas estrada aí que vocês tão vendo fica tudo lotada de ônibus, van, carro e tudo". (E., feminino)

É notável a inferência da igreja na cultura quilombola. Tradicionalmente, o terço e as orações das celebrações religiosas são cantados. Esta tradição é enaltecida e reconhecida por todos os membros da comunidade. D. Elenita, a líder da comunidade, é admirada por este dom: "Ela canta nas festa que eu quero que vocês vejam, vocês tem que ver a voz desta mulher" (D.F., feminino, referindo-se à líder da comunidade)

A religiosidade das famílias quilombolas e os hábitos que dela derivam demandam uma análise própria devido à imensidão de informações que se podem abstrair daí. Os cuidados com a saúde no grupo, por exemplo, possuem forte conexão com a religiosidade, as simpatias relatadas nas entrevistas, são um misto de magia e religião que serão alvos de futuras investigações, mais pontuais.

Também com as entrevistas, observou-se que as investidas do poder público e das instituições e organizações que tentam ajudar a comunidade não prosperam. A exemplo disso, está a cozinha comunitária, que não cumpre com a finalidade de alavancar remuneração na comunidade. A culinária, em nível industrial como é a proposta da cozinha comunitária, não faz parte dos hábitos de preparar alimentos das famílias quilombolas.

As práticas alimentares da comunidade são bastante específicas, em face da falta de terras para plantar seus próprios alimentos, os quilombolas se veem obrigados a comprar e como há escassez de recursos financeiros, as famílias optam por adquirir alimentos 
mais calóricos visando suprir a carência em termos de quantidade. Carnes, raras vezes são consumidas pelas famílias. (SOUZA, 2009).

Esmiuçando em entrevistas o apontamento do acesso à saúde como longe das famílias, constatou-se que a ingerência do poder público na saúde da comunidade se deu de forma desconectada com a realidade quilombola. A medicina vernacular praticada pelas famílias foi sobreposta pela forma biomédica (medicina formal).

Por muito tempo, as famílias daquela região não dispunham de atendimento médico, o que lhes forçou a traçar estratégias de sobrevivência, misturando suas crenças com magias e ervas em rituais místicos valendo-se apenas da fé e da agrobiodiversidade local.

Em outras regiões, mais afastadas e desassistidas, as comunidades locais encontram formas peculiares de resolverem seus problemas de saúde e cuidado com o corpo, recorrendo ao acervo de saberes e conhecimentos tradicionais, transmitidos oralmente e muitas vezes organizados em forma de narrativas míticas, imaginárias ou religiosas. (OLIVEIRA; BARTHOLO JUNIOR, 2008, p. 2).

Entretanto, após a construção de uma unidade básica de saúde na região, por um curto espaço de tempo, as famílias passaram a contar com um médico que atendia os pacientes durante o dia. $\mathrm{O}$ médico designado à comunidade passou a prescrever aos quilombolas remédios alopáticos de toda ordem, especialmente os anti-depressivos, os famosos "tarja-preta". A medicação se tornou contínua em meio as famílias, especialmente dentre as mulheres quilombolas. Segundo relatos, o médico desabonava todo tipo de crença em simpatias ou remédios caseiros apresentados pelas famílias. Ocorre que o poder público não sustentou por muito tempo o funcionamento da unidade de saúde na região. Nas últimas visitas, apurou-se que a comunidade não dispõe mais de atendimento médico, mas continua consumindo os remédios outrora prescritos.

O legado deixado pelo poder público àquelas famílias é perverso, desestrutura suas práticas culturais e altera a concepção do processo saúde-doença ${ }^{5}$ que as famílias tinham antes desta funesta ação. Mesmo assim, subsistem antigas formas de pensar a relação da saúde dentro da comunidade (imbricada em forma de rede, partilhada dentre outras comunidades). A rede, composta por benzedeiras da região, se auto alimenta e inibe a sua destruição frente ao capital, a ciência moderna, etc.

Diante da resistência constatada ao modelo biomédico mecanicista e à atuação falha do poder público na comunidade, percebe-se que a aculturação forçada que ocorre pela falta de percepção e respeito com o conhecimento tradicional daquelas famílias é outro fator que obstaculiza a conservação da cultura quilombola.

Têm-se, portanto, na territorialização da fármaco-medicina moderna, no hibridismo religioso da igreja evangélica e católica, nas ingerências externas por parte do poder público e da iniciativa privada, na ausência de terras para o plantio e a efetivação da posse

\footnotetext{
${ }^{5}$ Em síntese, pode-se dizer, em termos de sua determinação causal, que o processo saúde-doença representa o conjunto de relações e variáveis que produzem e condicionam o estado de saúde e doença de uma população que variam em diversos momentos históricos e do desenvolvimento científico da humanidade. (VIANNA, 2010, p. 82).
} 
(regularização fundiária), os principais impulsionadores da transição transformação dos hábitos culturais quilombolas e na ressignificação de seus símbolos e aportes imateriais.

\section{CONSIDERAÇÕES FINAIS}

Buscou-se com este artigo identificar quais são as particularidades da reprodução do patrimônio cultural quilombola, a partir da comunidade de Palmital dos Pretos, bem como as amarras que inibem a sua conservação. Na primeira seção foi retratada a histórica invisibilidade da população afrodescendente no estado do Paraná e os rumos que a busca pelos direitos sociais tem tomado.

Em que pese os avanços constatados, as comunidades tradicionais, sobretudo as quilombolas, ainda vivem à margem da sociedade, tanto do ponto de vista territorial como no acesso ao aparato estatal. Outro aspecto que insurge deste paradigma, é a ausência de responsabilidades bem delineadas no poder público.

A legislação que abarca o direito à terra aos quilombolas foi concebida em nível federal, entretanto, o reconhecimento de fato demanda o engajamento das esferas estadual e municipal, sendo a última, devido sua proximidade com o problema, a mais capacitada para desentranhar as amarras jurídicas que inibem a consecução deste e dos demais direitos aos remanescentes.

Na segunda seção, mostrou-se que a análise do patrimônio cultural de uma comunidade quilombola deve se dar da forma mais abrangente possível, considerando os aspectos materiais, como seus geossímbolos, e também o conhecimento tradicional presente no plano da imaterialidade das famílias quilombolas. Nesta esteira, entende-se que "conhecimento tradicional pode ser definido como o saber e o saber-fazer, a respeito do mundo natural e sobrenatural, gerados no âmbito da sociedade não urbano-industrial e transmitidos oralmente de geração em geração." (DIEGUES, 2000, p. 30).

Diante das dificuldades impostas na conservação da cultura quilombola, urge a necessidade de se explorar e catalogar os enunciados trazidos pela memória daquelas pessoas, especialmente as mais idosas. A análise no plano imaterial, deve ser, portanto, o principal foco de investigações vindouras.

Por fim, restou apurado na terceira seção, através da realização de entrevistas e aplicação de três ferramentas do diagnóstico rural participativo que a principal barreira que se coloca contra a conservação do patrimônio cultural quilombola é a morosidade na regularização fundiária.

A terra é pressuposto basilar para a manutenção da comunidade, dela derivam todas as outras práticas socioculturais. Os quilombolas, acima de tudo são agricultores e é a posse pacífica da terra que lhes assegurará a cidadania e o fortalecimento da comunidade, inclusive, nutrindo-a de força para fazer frente aos outros descentramentos de identidade que lhes atingem.

A ingerência da igreja, do poder público, empresas da iniciativa privada e toda e qualquer atuação destes junto à comunidade devem ter como mote central o 
fortalecimento da cultura quilombola e não a implementação quase que coercitiva de novos hábitos, como visualizou-se no decorrer do estudo. Assim, a cultura quilombola poderá ser revigorada e continuar a ser transmitida de geração em geração.

\section{REFERÊNCIAS}

BALDIN, Nelma; MUNHOZ, Elzira M. Bagatin. Snowball (bola de neve): Uma técnica metodológica para pesquisa em educação ambiental comunitária. In: I CONGRESSO NACIONAL DE EDUCAÇÃO EDUCERE, 2011, Curitiba. Anais. Curitiba: Ed. PUC-PR, 2011, n. 10, p. 1-13.

BONNEMAISON, Joel. Viagem em torno do território. In: CORREAA, R.; ROSENDAHL, Z. (orgs.) Geografia Cultural: um século. Rio de Janeiro: Ed. UERJ, 2003. p.83-131.

BRASIL. Constituição da República Federativa do Brasil: promulgada em 5 de outubro de 1988. Disponível em:<http://www.planalto.gov.br/ccivil_03/constituicao/constituicao.htm >. Acesso em: 23 jul. 2013.

Identificação, reconhecimento, delimitação, demarcação e titulação das terras ocupadas por remanescentes das comunidades dos quilombos de que trata o art. 68 do Ato das Disposições Constitucionais Transitórias. Disponível em: <http://www.planalto.gov.br/ccivil_03/decreto/2003/d4887.htm >. Acesso em: 23 jul. 2013.

CELINSKI, Marina Gabriela. Identidade - Retrato de uma Comunidade Quilombola. 2010. Trabalho de Conclusão de Curso (Bacharelado em Comunicação Social - Habilitação em Jornalismo) - Universidade Positivo. Curitiba, PR.

CONAQ. Coordenação Nacional das Comunidades Quilombolas. Manifesto da Coordenação Nacional das Comunidades Quilombolas. 2012. Disponível em: <http://www.petitiononline.com/conaq123/ petition.html> Acesso em: 10 out. 2013.

COSTA, Rogério Haesbaertda. O mito da desterritorialização: do "fim dosterritórios" à multiterritorialidade. 3.ed. Rio de Janeiro: Bertrand Brasil, 2004.

CUCHE, Denis. A noção de cultura nas ciências sociais. São Paulo: EDUSC, 1999. 130p.

FUNDAÇÃO PALMARES. Apresentação da Fundação Palmares. Disponível em: <http:/ /www.palmares. gov.br/quem-e-quem/>. Acesso em: 20 jul. 2013.

GONÇALVES, José Reginaldo Santos. O patrimônio como categoria de pensamento. In: ABREU, Regina; CHAGAS, Mário. (Orgs.). Memória e patrimônio: ensaios contemporâneos. Rio de Janeiro: DP\&A, 2003. p. 21-29.

HALL, Stuart. A identidade cultural na pós-modernidade. Rio de Janeiro: DP\&A, 1997.

GOMES JÚNIOR, Jackson; SILVA, Geraldo Luiz da; COSTA BRACARENSE, Paulo Afonso. Paraná Negro. Curitiba: UFPR/PROEC, 2008. 104 p.

LEITE, Ilka Boaventura. O projeto político quilombola: desafios, conquistas e impasses atuais. Estudos Feministas, Florianópolis, v. 16, p. 965-977, set.-dez. 2008.

LITTLE, Paul. E. Territórios sociais e povos tradicionais do Brasil: por uma antropologia da territorialidade. Brasília: UnB, 2002. 32 p.

MACDOWELL, Linda. A transformação da geografia cultural. In: GREGORY, Derek; MARTIN, Ron; SMITH, Grahan. (Orgs). Geografia humana: sociedade, espaço e ciência social. Rio de Janeiro: Jorge Zahar Editor, 1996.

OLIVEIRA, Marilía Flores Seixas de; BARTHOLO JUNIOR, Roberto dos Santos. Saberes e técnicas medicinais do povo brasileiro: corpo, magia e natureza, entre Pajés, Orixás e Caboclos. In: IV ENCONTRO NACIONAL DA ANPPAS, 2008, Brasília. Anais ...

OLIVEN, Ruben George. Patrimônio Intangível: considerações iniciais. In: ABREU, Regina; CHAGAS, Mário. (Orgs.). Memória e Patrimônio: ensaios contemporâneos. Rio de Janeiro: DP\&A, 2003. p. 77-80. 
SALLES, Jefferson de Oliveira; PORTO, Liliana; MARQUES, Sônia Maria dos Santos (Orgs.) Memórias dos Povos do Campo no Paraná. Centro-Sul. Curitiba: ITCG, 2013. 404 p.

SCHMITT, Alessandra; TURATTI, Maria Cecília Manzoli; CARVALHO, Maria Celina Pereira de. A atualização do conceito de quilombo: Identidade e território nas definições teóricas. Ambiente \& Sociedade, São Paulo, v. 1, n. 10, p. 1-10, jan./jun. 2002.

SOUZA, Ariane Cristina Ferreira de. Políticas públicas de segurança alimentar e nutricional da população negra: Um Resgate da Cultura Alimentar em Comunidades Quilombolas. 2009. Trabalho de Conclusão do Curso (Graduação em Nutrição) - Universidade Federal do Paraná. Curitiba, PR.

VARDEJO, Miguel Espósito. Diagnóstico Rural Participativo: Um guia prático. Brasília: Ministério do Desenvolvimento Agrário, 2006.

VIANNA, Lucia Amaral Carneiro. Processo Saúde-Doença. In: Especialização em Saúde da Família.

São Paulo: UFSP/ Ministério da Saúde, 2010. p. 71-92.

Recebido para avaliação em 29-04-2014

Aceito para Publicação em 31-07-2014 